\title{
一颗 $\mathrm{K}$ 型超巨星脉动的证据和初步分析
}

\author{
刘学富 李志安郭子和彭松泉 谭微松 \\ （北京师范大学天文系）（北京天文台）（云南天文台）
}

近年来, 晚型超巨星大气的物理状态和活动愈来愈引起人们的极大重视. 对这类星的精 确光电观测和光谱分析对研究恒星的演化规律和恒星大气结构有着重要意义. $\zeta$ Aur 食双星 系统中 $\mathrm{K}$ 型子星是颗红超巨星, 它具有庞大的色球层, 且有激烈的色球活动 ${ }^{[1]}$. 在全食期间, $B$ 型子星被 $\mathrm{K}$ 型子星掩食, 这时是研究 $\mathrm{K}$ 型超巨星大气物理状况与活动的极好机会. 为此我 们在 1979 年 12 月 24 日至 1981 年 2 月 27 日期间内对 5 Aur 系统中的 K 型超巨星进行了窄 波段的光电观测和光谱观测并对观测资料进行了自回归谱分析 (AR 谱分析), 分析结果说明 光电观测所得光变曲线和光谱测得一些谱线的等值宽度变化和视向速度变化等 结 果 相 当一 致,都揭示出此 $\mathrm{K}$ 型超巨星具有几十分钟的准周期脉动.

\section{一、观测证据}

在 1979-1980 年 $\zeta$ Aur 食期间在北京天文台用 60 公分反射望远镜对 $\zeta$ Aur 做了 UBV 及六个窄波段的光电测光 ${ }^{[2]}$. 其中在全食期间 12 月 24 日至 27 日对 $\mathrm{K}$ 型子星专门做了 $\mathrm{H}_{\alpha}$ 窄 波段的光电测光. 比较星为 $2 \mathrm{Aur}$ (K3III). 测得 $\mathrm{H}_{a}$ 波段的光变曲线如图 1 所示. 此外 1981 年 2 月 26 日至 28 日对该星又进行了 $6050 \AA$ 及 $3940 \AA$ 窄波段的光电测光, 其光变曲线参见 图 2. 光变曲线显示出有 15 分钟至 90 分钟的准周期变化, 光变幅从 0.05 至 0.12 .

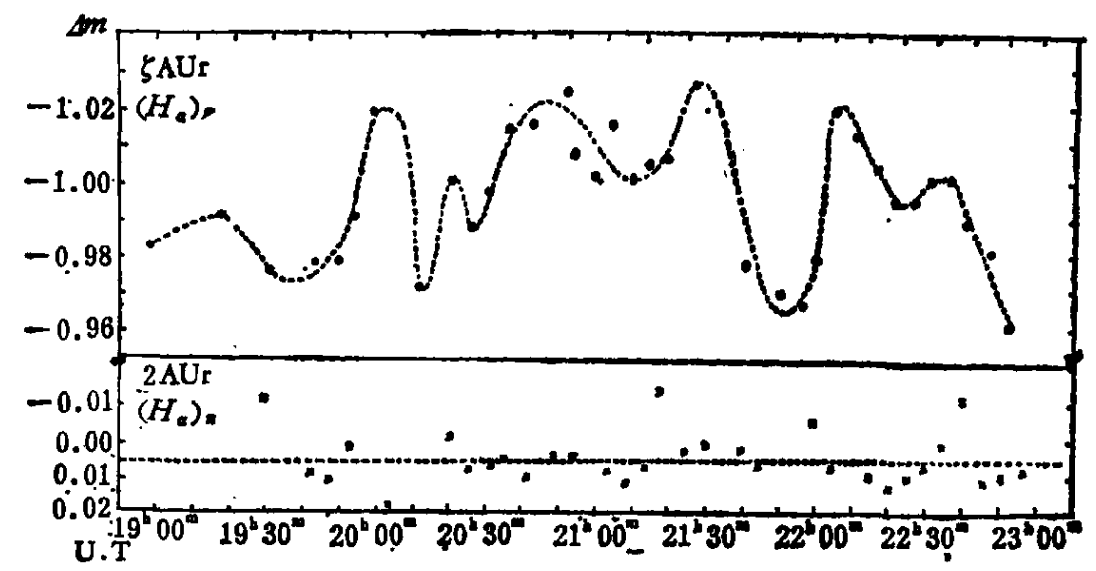

图1 1979 年 12 月 24 日至 25 日 $\mathrm{H}_{a}$ 窄波段的光变曲线

光谱分析的资料是在 1981 年 2 月 24 日晚用云南天文台一米望远镜的卡焦摄谱仪拍掫 的. 对 $225500 \AA-6800 \AA$ 波段用 $103 \mathrm{af}$ 底片相继拍了八张底片, 每张底片暴光时间为八分钟 或十分钟. 光谱片的线色散为 $44 \AA / \mathrm{mm}$. 图(3)为依时间顺序排列的八张底片所拍的 $\zeta \mathrm{Aur}$ 光谱段 $(225500 \AA-6800 \AA)$ 的密度曲线. 由图 3 明显看出连续谱和㙕线随时间而变化. 我

本文 1981 年 10 月 8 日收到. 


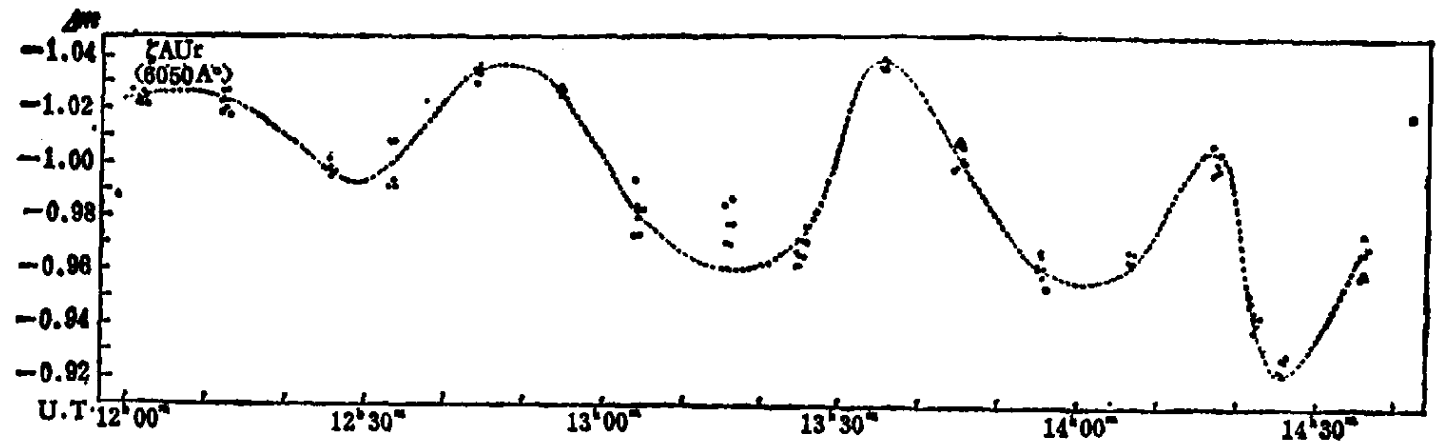

图21981年2月26日至 27 日 $6050 \AA$ 窄波段的光变曲线

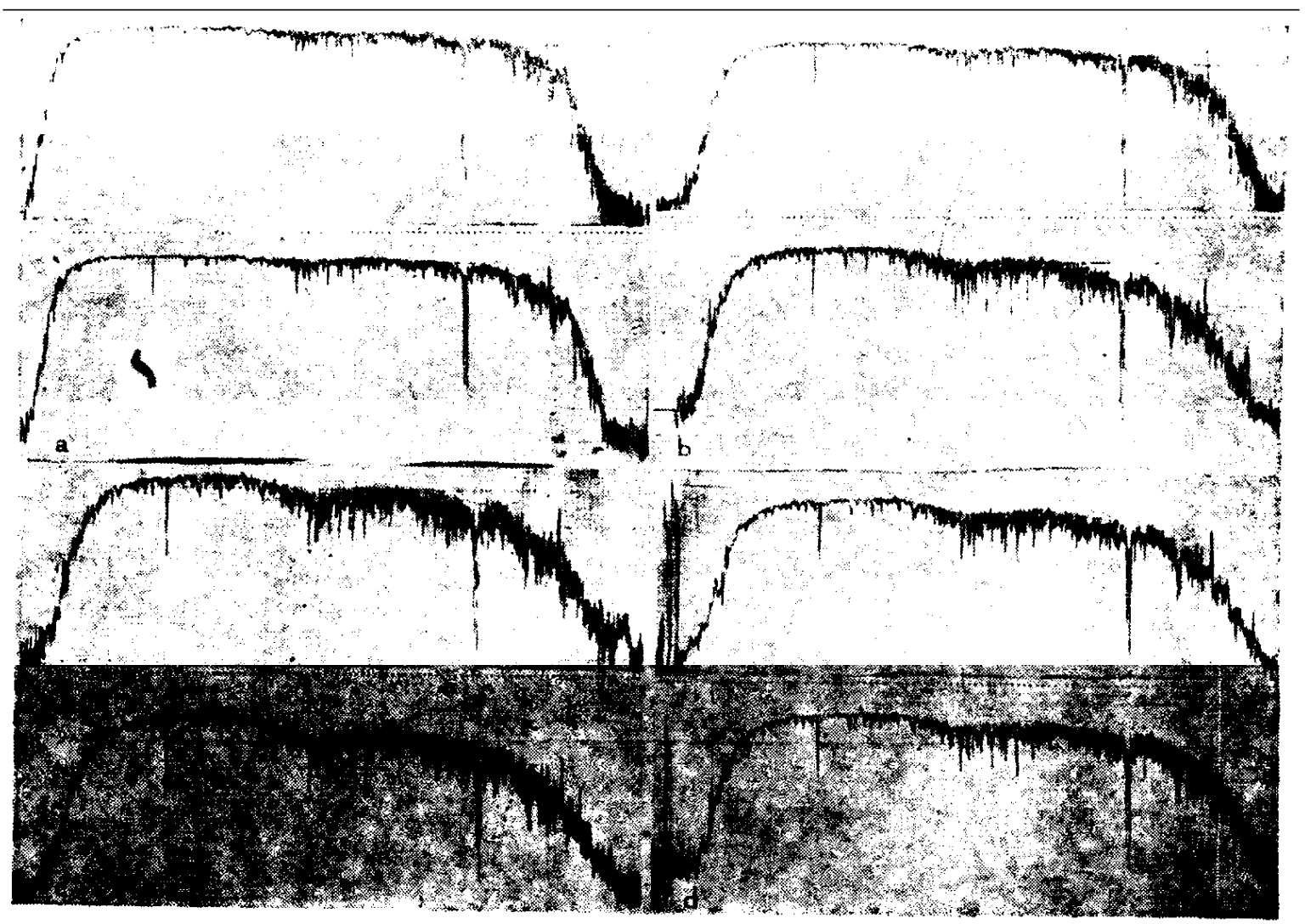

图 35 Aur $\lambda 25500 \AA-6800 \AA$ 光谱段的密度描迹图

们测量连续谱时参照了分光标准星 $\alpha \mathrm{B} 00$ 的分光光度图, 选取了五个基本上不大受吸收线影 响的波段测量出相对强度,并作了大气消光改正. 此外, 测量了 $H_{a}$ 线及 NaI 的双重线的等值 宽度 $\left(W_{2}\right)$ 及线心深度 $\left(R_{2}\right)$ 及谱线位移, 求出了 $W_{2}$ 和 $R_{2}$ 及视向速度 $\left(U_{r}\right)$ 随时间的变 化曲线(如图 4 所示), 其结果数据列在表 1.

由帕那连续谱的斜率变化可以求出该星的温度变化. 我们利用观测波段连续谱的能量分 布变化求出该星在脉动过程中此波段范围的色温度最大变化有 690 K。.

我们按照 Wright 给出的轨道要素 ${ }^{[1]}$ 计算出 $\mathrm{K}$ 型子星当时的标准视向速度为 4.9 公里/秒 （图 4 以中央的横实线标出）. 显然视向速度曲线是围绕着这条标准速度线作准周期性的变 化,其周期和变幅与连续谱的变化相同, 只是位相滞后 $180^{\circ}$. 这种现象证明恒星呈现出准周期 生脉动. 按照这种观点我们计算出此 $\mathrm{K}$ 型超巨星由于脉动引起的最大半经变化约为 $2.3 \times 10^{4}$ 公里. 由于恒星大气层存在着速度梯度,所测视向速度会比实际光球脉动速度大些. 
表 $1 H_{a}$ 线及 $\mathrm{NaI}$ 双重线的 $\mathrm{W}_{2}, \mathrm{R}_{c}$ 和 $\mathrm{U}_{\mathrm{r}}$ 随时间的变化

\begin{tabular}{|c|c|c|c|c|c|c|c|c|c|}
\hline \multirow{3}{*}{$\begin{array}{c}\text { 日期 } \\
\text { J. D. hel } \\
2444000+\end{array}$} & \multirow{2}{*}{\multicolumn{3}{|c|}{$\frac{H_{\alpha}}{6615.839 \AA}$}} & \multicolumn{6}{|c|}{$\mathrm{NaI}$} \\
\hline & & & & \multicolumn{3}{|c|}{$5895.793 \AA$} & \multicolumn{3}{|c|}{$5889.953 \AA$} \\
\hline & $\begin{array}{c}U_{\mathrm{r}} \\
(\text { 公里/秒) }\end{array}$ & $\mathrm{w}_{2}(\AA)$ & $\mathrm{R}_{\mathbf{z}}$ & $\begin{array}{c}\mathrm{U}_{\mathrm{r}} \\
\text { (公里/㧛) } \\
\end{array}$ & $w_{\lambda}(\AA)$ & $\mathbf{R}_{2}$ & $\begin{array}{c}\mathrm{U}_{2} \\
\text { (公里/利) }\end{array}$ & $w_{2}(\AA)$ & $\mathbf{R}_{\mathbf{\lambda}}$ \\
\hline 660.12970 & 9.27 & 1.989 & 0.656 & 6.74 & 2.200 & 0.6757 & 4.44 & 3.534 & 0.7109 \\
\hline 660.14914 & 6.90 & 2.032 & 0.630 & -3.3 & 2.384 & 0.6046 & -8.96 & 2.578 & 0.6541 \\
\hline 660.16025 & 21.41 & 1.874 & 0.544 & -0.51 & 2.645 & 0.5715 & 5.67 & 4.186 & 0.7400 \\
\hline 660.16720 & 8.58 & 1.570 & 0.538 & 11.26 & 2.924 & 0.6092 & 7.80 & 5.052 & 0.7103 \\
\hline 660.17900 & 7.89 & 1.702 & 0.586 & -6.64 & 3.008 & 0.6749 & 0.20 & 4.462 & 0.7772 \\
\hline 660.18525 & 3.94 & 1.958 & 0.630 & 1.61 & 2.342 & 0.6666 & 1.98 & 3.855 & 0.7891 \\
\hline 660.19255 & 18.74 & 1.676 & 0.569 & 7.75 & 3.527 & 0.6533 & 3.06 & 3.379 & 0.7302 \\
\hline 660.20400 & 27.63 & 1.830 & 0.556 & 0.72 & 3.357 & 0.6994 & 2.65 & 4.983 & 0.7650 \\
\hline
\end{tabular}

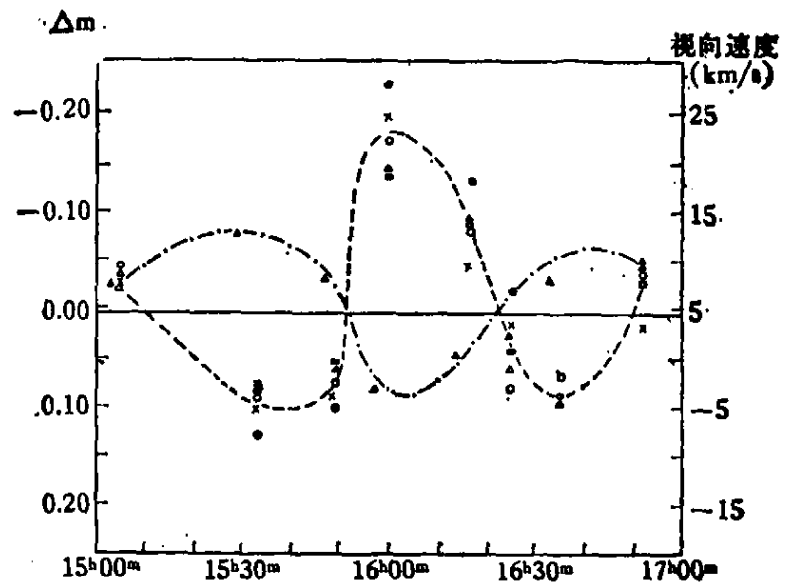

图 4 视向速度曲线 (锁线)及连续谱相对强度变化曲线 (虚线)

图中标记: $6615.8 \AA(\bullet) ; 6589.3 \AA(X) ; 6483.2 \AA(\square)$; $6556.7 \AA(\Delta) ; 6430.2 \AA(0)$

\section{二、观测资料的 $\mathbf{A R}$ 谱分析}

我们对光电观测的资料和光谱处理的资料分别作了自回归谱分析 (AR $)^{[3]}$. 首先对各天 资料分别进行平滑内插得到各观测序列对应的平稳序列, 然后再分别进行 AR 谱分析得到各 观测序列存在的主要周期 (如表 2 所示). 根据得到的周期再作调和分析, 得出各周期项所对 应的振幅和位相 (表 3).

表 2 AR 谱分析结果

\begin{tabular}{|c|c|c|c|c|c|c|c|}
\hline 日 期 & 波段 & & & 周 & 期（天） & & \\
\hline $1981.2 .26 / 27$ & $6050 \AA$ & 0.0647 & 0.0301 & 0.0208 & 0.0151 & - & 0.0109 \\
\hline $1981.2 .26 / 27$ & $3940 \AA$ & 0.0833 & - & 0.0224 & 0.0156 & 0.0123 & 0.0102 \\
\hline $1979.12 .24 / 25$ & $\mathrm{H}_{a w}$ & 0.0699 & 0.0460 & 0.0257 & 0.0136 & - & - \\
\hline $1979.12 .24 / 25$ & $\mathbf{H}_{\boldsymbol{\alpha} \mathbf{n}}$ & 0.0624 & 0.0291 & 0.0230 & - & - & - \\
\hline $1979.12 .26 / 27$ & $\mathrm{H}_{a \omega}$ & 0.0624 & 0.0301 & 0.0194 & 0.0148 & - & - \\
\hline $1979.12 .26 / 27$ & $\mathrm{H}_{\alpha \mathbf{n}}$ & 0.0530 & - & 0.0194 & - & - & - \\
\hline 1981.2 .24 & $F_{\alpha}(6483 \AA)$ & - & 0.0397 & 0.0265 & 0.0190 & 0.0130 & - \\
\hline 1981.2 .24 & $F_{2}(5741 \AA)$ & - & 0.0448 & 0.0230 & - & 0.0132 & - \\
\hline
\end{tabular}


衰 3 各主要周期项对应的振幅和位相

\begin{tabular}{|c|c|c|c|c|c|c|}
\hline 日 & $1981.2 .26 / 27$ & $1981.2 .26 / 27$ & $1979.12 .24 / 25$ & $1979.12 .24 / 25$ & $1979.12 .26 / 27$ & $1979.12 .26 / 27$ \\
\hline 波段 & $6050 \AA$ & $3940 \AA$ & $\left(\mathrm{H}_{a}\right)_{w}$ & $\left(\mathrm{H}_{a}\right)_{0}$ & $\left(\mathrm{H}_{0}\right)_{w}$ & $\left(H_{0}\right)_{0}$ \\
\hline 周期(天) & 0.0647 & 0.0833 & 0.0699 & 0.0624 & 0.0194 & 0.0530 \\
\hline 层偪(星等) & 0.028 & 0.011 & 0.007 & 0.009 & 0.010 & 0.011 \\
\hline 相位（度） & 56.7 & 191.1 & 8.1 & 225.0 & 90.6 & 217.5 \\
\hline 周期(天） & 0.0301 & 0.0224 & 0.0136 & 0.0291 & & 0.0194 \\
\hline 振愢（星等） & 0.054 & 0.068 & 0.005 & 0.018 & & 0.006 \\
\hline 相位(度) & 76.3 & 175.4 & 208.0 & 222.6 & & 180.0 \\
\hline 周期(天) & 0.0208 & 0.0123 & & 0.0230 & & \\
\hline 据愊(星等) & 0.039 & 0.080 & & 0.013 & & \\
\hline 相位(度) & 157.1 & 103.6 & & 209.9 & & \\
\hline 周期(天) & 0.0109 & 0.0102 & & & & \\
\hline 振愢（星等） & 0.012 & 0.045 & & & & \\
\hline 相位(度) & 80.9 & 209.4 & & & & \\
\hline
\end{tabular}

\section{三、讨 论}

根据观测事实, 我们认为 $\zeta$ Aur 食双星系统中的 $\mathrm{K}$ 型超巨星确实存在着短时标约几十分 钟的准周期性非径向脉动, 其变幅从 0.05 至 0.0 . 12 不太规则的变化. 这种现象看来很类似于 太阳光球大气的五分钟周期的振荡. 这个超巨星非径向脉动的物理机制尚须进一步研究. 一 方面要考虑到 B 型热子星大气中的赖曼 (Lyman) 量子对 $\mathrm{K}$ 型子星大气的湤发和电离作用(外 界因意), 更重要的应考虑超巨星内大气物质的运动规律和物理状态 (内因), 因为外因是通过 内因起作用. 我们的观测和初步分析仅为此提供了点滴资料，还有待于今后取得大量精确的 观测资料和细致的分析，以便进一步探讨.

[1] Wright, K. O., Vistas in Astronomy, 12(1970), 147.

[2]极于和、刘学宾、贾贵山, 天体物理学报, 1(1981),3: 203 .

[3] 部大伟、过铭,天文地球动力学文柋, 1978,96.

[4] 刘学吉、部玉莲等,科学通报,26(1981),22: 1375 .

[5] Strohmeier, W., Variable Stars, 1972, 90-147. 